\title{
A Fuzzy Cognitive Map Model for Estimating the Repercussions of Greek PSI on Cypriot Bank Branches in Greece
}

\author{
Maria Papaioannou ${ }^{1}$, Costas Neocleous ${ }^{2}$, and Christos N. Schizas ${ }^{1}$ \\ ${ }^{1}$ University Ave., Department of Computer Science, University of Cyprus, Nicosia, Cyprus \\ cs03pm2@cs.ucy.ac.cy, schizas@ucy.ac.cy \\ 231 Archbishop Kyprianos Str, Cyprus University of Technology, Limassol, Cyprus \\ costas.neocleous@cut.ac.cy
}

\begin{abstract}
Recently, Greece experienced a financial crisis unprecedented in its modern history. In May of 2010 Greece signed a bailout memorandum with Troika (a tripartite committee constituted by the European Central Bank, the European Commission and the International Monetary Fund). In February of 2012, they proceeded to a second bailout package along with a debt restructuring deal that included a private sector involvement (PSI). The overall loss, for the private investors, was equivalent to around $75 \%$. Due to the strong economic ties between Greece and Cyprus, PSI had a substantial impact on the Cypriot economy. A fuzzy cognitive map (FCM) system has been developed and used to study the repercussions of the Greek PSI on the economic dynamics of Cyprus and more specifically on the probability of cutting off the Cypriot Bank branches that operate in Greece. The system allows one to observe how a change on some parameters can affect the stability of the rest of the parameters. Different promising scenarios were implemented, scaling the percentage of PSI from $0 \%$ to $80 \%$.
\end{abstract}

Keywords: Fuzzy Cognitive Maps, Intelligent Systems, Private Sector Involvement.

\section{Introduction}

In 2008 the subprime mortgage crisis appeared in USA which was a crucial factor that led to the emersion of the recent global financial crisis. Inevitably, this introduced adverse economic effects for most of the European countries. That along with a combination of other factors resulted in the economic victimization of the weakest European economies (e.g. Greece, Portugal, Ireland, and Cyprus). There was a widespread fear that a failure to deal with the national debt crisis could have created a domino effect for the other members of the Eurozone. Greece was the first country which had to deal with the possibility of a national bankruptcy in 2009. As a result of the continuous strong increase in Greek government debt levels, Greece`s sovereign-debt was downgraded by the International Credit Rating Agencies to junk status in April 2010. 
There was a fear that other countries could be affected by the Greek economic crisis. This forced Europe to take important and decisive corrective actions under time pressure. In May of 2010, Troika which is a tripartite committee constituted by the European Central Bank, the European Commission and the International Monetary Fund (IMF), agreed to give Greece a three-year $€ 110$ billion loan. As part of the deal with Troika, the Greek government implemented a series of austerity measures. These, led Greece's recession even deeper. As a result, in February of 2012 Troika decided to provide Greece a second bailout package accompanied with a restructure agreement with private sector involvement (PSI). The debt restructuring deal declared that private holders of Greek government bonds had to accept a $53.5 \%$ so-called "haircut" to their nominal values. Eventually, in March 2012, the bond swap was implemented with an approximately $75 \%$ nominal write-off.

Since the Greek and the Cypriot economies are strongly related and connected, this led to serious repercussions to the Cyprus economy. More specifically, the Cypriot banking system, which constitutes one of the pillars of the Cyprus economy, suffered from the Greek PSI, since it was highly exposed to the Greek government bonds. Consequently, that had a great impact on Cyprus economy which had already been dealing with economic problems. The future of Cypriot economy and banking system seemed uncertain. The Government of Cyprus and the Cypriot bankers had to deal with an unprecedented situation which was extremely difficult to handle since they could not estimate the overall impact of the Greek PSI on Cyprus economy and Cypriot banking system.

In the current work reported in this paper an attempt is made to model the dynamics of the above problem using the technology of fuzzy cognitive maps (FCM). That is, to study the long term impacts on the Cyprus economy and on the banking system as a result of the Greek PSI.

FCM modelling constitutes an alternative way of building intelligent systems, using uncertain parameters that influence one - another. Such a system is constituted by certain concepts (which are characterized by a state) along with relevant interconnections (which are described by sensitivity values). Essentially, an FCM is developed by integrating the existing experience and knowledge regarding a cause - effect system in a pseudo-dynamic manner. An FCM provides the opportunity to predict the final states of the system caused by a change on the initial concept states. After a change is applied to selected initial states of the concepts of interest, the system is let to evolve for a number of steps until the concept states converge to stable values. Further analysis and work can be done on the converged final states of the system for understanding how indirect cause - effect relations drive the system's behaviour.

There is a wide range of interesting FCM applications [1, 2, 8, 10, and 11] in modelling complex dynamic systems such as medical, environmental, supervisory and political systems.

This study aims to examine the impact of the Greek PSI on the possibility of Cypriot banks cutting off the Cypriot branches which operate in Greece. Such a scenario seemed impossible and far from reality back in April of 2012, at the time when this FCM system was originally developed and tested. 


\section{The FCM System}

A wide range of real life dynamical systems are characterized by causality through their interrelations. Most of the times, experienced and knowledgeable users can identify the important parameters and their interactions in the system. However, the complexity of these systems acts as a prohibitive factor on prognosis of their future states. In many practical situations, it is crucial for the decision makers to have an estimate on the cost of changing a state of a concept and how will affect other concepts of interest. FCMs are a soft computing methodology of modeling dynamic systems, which constitute causal relationships amongst their parameters. They manage to represent human knowledge and experience, in a certain system's domain, into a weighted directed graph model and apply inference presenting potential behaviours of the model under specific circumstances. The parameters are led to interact until the whole system reaches equilibrium. FCMs allow a user to reveal intricate and hidden in the already known causal relationships of the concepts and to take an advantage of the causal dynamics of the system in predicting potential effects under specific initial circumstances.

Two knowledgeable persons were asked to contribute to the development of the current FCM system. In the first place, they had to identify the most important factors that constitute the modeled system. These factors comprise the set of the concepts that were used to simulate the FCM model. Additionally, they had to define the states of the FCM concepts as they were in April of 2012. The states were described by a numeric value from 0 to $1(0$ to $100 \%)$, whereas 0 meant that the activation of the particular concept is the minimum possible, and 1 that the concept's activation is maximum possible. Additionally, they had to describe the degree of variation they expect to see, in the final state of every concept after the implementation of the Greek PSI. To be better guided, they first established whether the change will be positive or negative and then defined the intensity of the variation choosing amongst \{low, medium, high\}.

The next phase of development requested the experts to define the causal relations between the interconnected concepts. Each relation is characterized by a numeric value called sensitivity (or influence coefficient, or weight). In this study a slightly different methodology than that used in the conventional FCMs has been used when defining the sensitivities. The sensitivity of the relation describes the impact of changing the state of $\mathrm{C}_{\mathrm{i}}$ on the concept $\mathrm{C}_{\mathrm{j}}$. The equation that was used to calculate the sensitivities, in this study, is given in Equation (1):

$$
S_{i j}=\frac{\delta C_{j}^{t+1, t}}{\delta C_{i}^{t, t-1}}=\frac{C_{j}^{t+1}-C_{j}^{t}}{C_{i}^{t}-C_{i}^{t-1}}
$$

where $t$ is the iteration counter.

Thus, in order to define the sensitivity of every relation, the experts had to make the following assumption: "The states $C_{i}^{t-1}$ and $C_{j}^{t}$ are equal to the initial values of the corresponding concepts as defined in the previous stage of development" and then 
answer the following question: "If the state of the concept $C_{i}$ becomes $x$ (in equation (1) is denoted by $C_{i}^{t}$ ) what will be the new state of concept $C j$ (denoted by $\left.C_{j}^{t+1}\right)$ ?". Consider for example the relation between the "Level of Cyprus economy" (C13) and the "Evaluation of the Cyprus Economy by Authoritative Rating Agencies" (C8). The experts defined the initial states of $\mathrm{C} 13$ and $\mathrm{C} 8$ as 0.5 and 0.2 respectively. Furthermore, they expected a negative relationship of medium intensity of the degree of variation of the level of Cyprus Economy as a result of the Greek PSI. Therefore the question for this sensitivity was finally formed as:

"If the level of Cyprus Economy gets reduced from 0.5 to 0.2 , what will be the new state of the concept "Evaluation of the Cyprus Economy by Authoritative Rating Agencies" if now is 0.2?". For this example the experts answered 0.05. However, measuring the change of the two consequent states of a concept, as a percentage of its initial value gives a better feeling about the strength of the variation. So this sensitivity value is calculated as:

$$
S_{13,8}=\frac{(0.05-0.2) / 0.2}{(0.2-0.5) / 0.5}=\frac{-0.15 / 0.2}{-0.3 / 0.5}=1.25
$$

Finally the sensitivities are divided by the number of iterations the system needs to converge. For this system this number was 10 and yet the final value of $S_{13,8}=0.125$. That is called the "absolute sensitivity".

Thus, using equations (1) and (2), the equation giving the total accumulated change in the activation of concept $C_{j}$ due to changes in concepts $C_{i}$ in discrete time is given by:

$$
C_{j}^{t+1}=C_{j}^{t}+\sum_{i}^{n} s_{i j} *\left(C_{i}^{t}-C_{i}^{t-1}\right) * \frac{C_{j}^{t}}{C_{i}^{t-1}}
$$

where $t$ is the iteration counter, $C$ is the activation strength of the concept of interest and $s_{i j}$ is the sensitivity (weight) which is a measure on how much a change in the current standing of concept $C_{i}$ affects the changes in the standing of concept $C_{j}$.

The methodology used to develop this FCM system differs from other previously proposed methodologies in the following respects. Firstly the weights are defined taking in mind the impact caused on a concept by the change of the other concept when each concept had been rationalized to a scale of 0 to $100 \%$. Secondly there was no use of squashing functions to smooth out the activation levels of the concepts such as the logistic function.

Therefore using only the activation function (3) the system is let to simulate after a change of the initial states for a number of iterations until it converges to stable states. Then the user of the system may observe and make conclusions on the direct or indirect effects of that change reflected on the final states of the system

\section{The FCM Concepts}

After a series of discussions, the experts concluded that they had to use 15 influencing parameters as shown in Table 1. These are the most significant concepts of the 
system. The experts had to also decide on the initial value of each concept. Although these concepts are difficult to be objectively quantified, the experts tried to document their decisions, mostly through referring to the press and from relevant statistical information. However, many of the parameters are too complex to be analysed and described based on raw numbers. For example the concept "Level of Cyprus Economy" encompasses characteristics like GDP, unemployment rate, housing, Consumer Price Index, stock market prices, industrial production, etc. In such cases the experts had to define the state of the concept based only on their "feeling" and their understanding of the dynamics of the system.

The initial values describing the states of the concepts as they were in April of 2012 are also given in Table 1. Besides the initial states of the concepts the experts were also asked to define the degree of variation of each concept and the sensitivities of their causal interrelations as described in the previous section. Inevitably, there were some discrepancies between the values given by each expert. Eventually, the average of the sensitivities was used to form the final sensitivity matrix which is presented in Table 2.

\section{$4 \quad$ Results and Conclusions}

This study aimed to observe how a change into the percentage of the Greek PSI (concept C3) affects the probability that the Cypriot banks eliminate their branches in Greece (concept C15). Ten scenarios with different percentages of Greek PSI were tested using the FCM system with the initial values (Table 1) and the average sensitivities of Table 2 given by experts. The response of the concept $\mathrm{C} 15$ to the variation of $\mathrm{C} 3$ is shown in Figure 1.

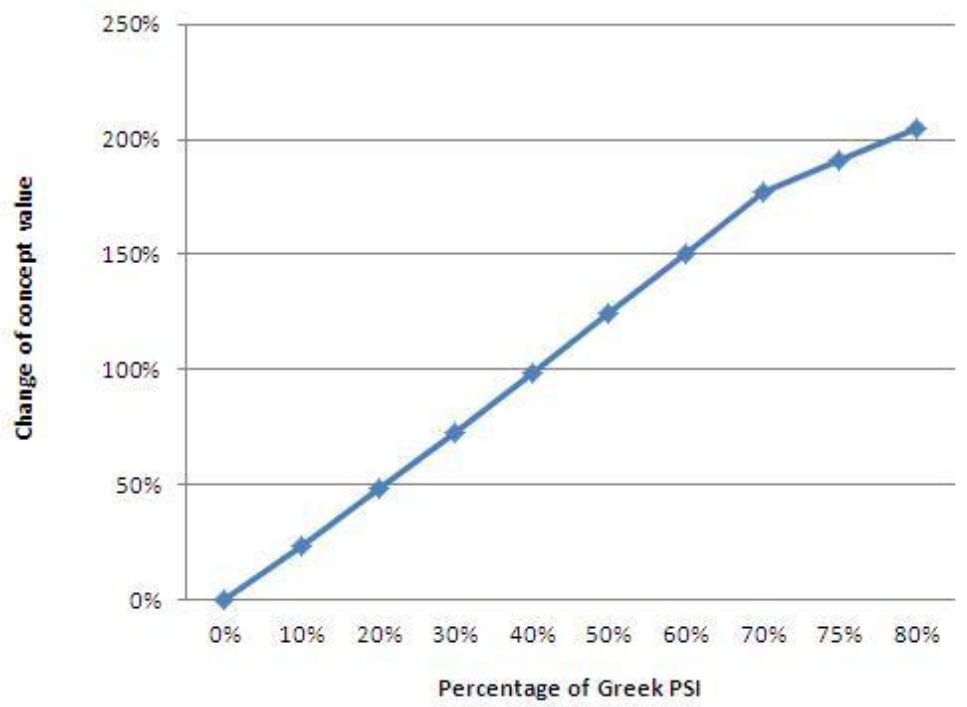

Fig. 1. Effect on the probability of cuttof of the Cypriot Bank branches that operate in Greece based on average sensitivities 
In Figure 1 the horizontal axis is showing the locked (not allowed to change) values of the Greek PSI starting from $0 \%$ to $80 \%$ (where $0 \%$ means that there was no implementation of the PSI and $80 \%$ means that the PSI was $80 \%$ ). The vertical axis is showing the degree of the change that happens to the concept $\mathrm{C} 15$ in respect to its initial value, due to Greek PSI variations. The changes to the values of C15 are calculated after the system settles and converges to a stable state. Then the percentage change is calculated between the final state value of the concept $\mathrm{C} 15$ and its initial value.

When working with an FCM model the actual final values of the concepts are not the objective but rather the trends. This is what a decision maker usually wants. Furthermore, it is important to note that during the developmental phase of the system, the experts expected that the probability of cutting of the Cypriot branches in Greece would have remained low regardless of the degree of the change in Greek PSI. That is why they set a low degree of variation for the corresponding concept. It was surprising though that when the system converged, the system predictions showed an opposite result. That is, the aforementioned probability is significantly increased when the percentage of the Greek PSI is increased. More specifically when the Greek PSI is $75 \%$ (which reflects the reality) then the probability of eliminating the Cypriot branches in Greece is increased by about $191 \%$ of its initial value (as given in Table 1). The system revealed that there exist strong causal paths connecting the two concepts.

Unfortunately for the Cypriot economy, the results given from the system were fully confirmed in reality few months later. In March of 2013, the Marfin Popular Bank and the Bank of Cyprus, two of the largest banks in Cyprus, sold their branches to Piraeus Bank of Greece.

Nevertheless, it is indicated yet again that the whole system is built based on the two experts' apprehension of the Greek and Cypriot economy. Consequently, this model does not necessarily represent fully the Greek and Cypriot economies or their interrelations. The system could benefit reliability and objectivity by the involvement of more expert opinions and the incorporation of the public opinion (e.g. by giving questionnaires to a big sample of people).

Beyond that, FCMs can be important tools for helping humans to make wiser and more accurate decisions, by presenting them the evolution of the modeled system after a set of changes and the final future consequences of their possible choices. That is why future work must be done to encounter the several open issues [7] concerning FCMs aiming in increasing their credibility and fine-tuned operation.

Acknowledgements. This research was partly supported by the University of Cyprus, the Cyprus University of Technology, and the Cyprus Research Promotion Foundation structural funds (TПЕ/OPIZO/0308(BE)/03). Special thanks to Dr Pambos Papageorgiou, MP for the very valuable discussions we had with him. 


\section{References}

1. Andreou, A.S., Mateou, N.H., Zombanakis, G.A.: The Cyprus puzzle and the Greek - Turkish arms race: Forecasting developments using genetically evolved fuzzy cognitive maps. Defence and Peace Economics 14(4), 293-310 (2003)

2. Bertolini, M., Bevilacqua, M.: Fuzzy Cognitive Maps for Human Reliability Analysis in Production Systems. In: Kahraman, C., Yavuz, M. (eds.) Production Engineering and Management under Fuzziness. STUDFUZZ, vol. 252, pp. 381-415. Springer, Heidelberg (2010)

3. Carvalho, J.P.: On the semantics and the use of fuzzy cognitive maps and dynamic cognitive maps in social sciences. Soft Computing in the Humanities and Social Sciences 214, 6-19 (2013)

4. Groumpos, P.P.: Fuzzy Cognitive Maps: Basic Theories and Their Application to Complex Systems. In: Glykas, M. (ed.) Fuzzy Cognitive Maps. STUDFUZZ, vol. 247, pp. 1-22. Springer, Heidelberg (2010)

5. Hanafizadeh, P., Aliehyaei, R.: The Application of Fuzzy Cognitive Map in Soft System Methodology. Systemic Practice and Action Research 24(4), 325-354 (2011)

6. Mateou, N.H., Andreou, A.S.: A framework for developing intelligent decision support systems using evolutionary fuzzy cognitive maps. J. Intell. Fuzzy Syst. 19(2), 151-170 (2008)

7. Neocleous, C., Schizas, C., Papaioannou, M.: Important issues to be considered in developing fuzzy cognitive maps. In: 2011 IEEE International Conference on Fuzzy Systems (FUZZ), pp. 662-665 (2011)

8. Neocleous, C., Schizas, C., Papaioannou, M.: Fuzzy cognitive maps in estimating the repercussions of oil/gas exploration on politico-economic issues in Cyprus. In: 2011 IEEE International Conference on Fuzzy Systems (FUZZ), pp. 1119-1126 (2011)

9. Neocleous, C., Schizas, C.N.: Modeling socio-politico-economic systems with time-dependent fuzzy cognitive maps. In: 2012 IEEE International Conference on Fuzzy Systems (FUZZ-IEEE), pp. 1-7 (2012)

10. Papageorgiou, E.I., Aggelopoulou, K.D., Gemtos, T.A., Nanos, G.D.: Yield prediction in apples using Fuzzy Cognitive Map learning approach. Comput. Electron Agric. 91, 19-29 (2013)

11. Sperry, R., Jetter, A.J.: Fuzzy cognitive maps to implement corporate social responsibility in product planning: A novel approach. In: 2012 Proceedings of the Technology Management for Emerging Technologies (PICMET), PICMET 2012, pp. 2536-2541 (2012) 


\section{Appendix A}

Table 1. The various influencsing parameters that have been studied and their initial values as set by the experts

\begin{tabular}{|l|l|c|}
\hline & CONCEPT NAME & INITIAL VALUE \\
\hline C1 & Cost of Money & $50 \%$ \\
\hline C2 & Liquidity of Cyprus Banks & $60 \%$ \\
\hline C3 & Degree of PSI of Greek Government Bonds & $0 \%$ \\
\hline C4 & $\begin{array}{l}\text { Degree of Deposits of Greek citizens and companies in } \\
\text { Cyprus Banks }\end{array}$ & $40 \%$ \\
\hline C5 & $\begin{array}{l}\text { Degree of Deposits of Cypriot citizens and companies in } \\
\text { Cyprus Banks }\end{array}$ & $\begin{array}{l}\text { Degree of Success of Bank Recapitalization by Private Equi- } \\
\text { ty }\end{array}$ \\
\hline C7 & Stock Market Value of Banks & $20 \%$ \\
\hline C8 & $\begin{array}{l}\text { Evaluation of the Cyprus Economy by Authoritative Rating } \\
\text { Agencies }\end{array}$ & $40 \%$ \\
\hline C9 & $\begin{array}{l}\text { Confidence of People and companies in Cyprus Banking } \\
\text { system }\end{array}$ & $80 \%$ \\
\hline C10 & Level of Greek Economic Crisis & $80 \%$ \\
\hline C11 & Level of Greek workforce that comes to Cyprus for work & $60 \%$ \\
\hline C12 & $\begin{array}{l}\text { Degree of Bank Recapitalization done by the Republic of } \\
\text { Cyprus }\end{array}$ & $50 \%$ \\
\hline C13 & Level of Cyprus Economy & $50 \%$ \\
\hline C14 & $\begin{array}{l}\text { Probability of the Republic of Cyprus entering EU Support } \\
\text { Mechanism }\end{array}$ & $30 \%$ \\
\hline C15 & $\begin{array}{l}\text { Probability of Cutoff of the Cypriot Bank branches that } \\
\text { operate in Greece }\end{array}$ & $20 \%$ \\
\hline
\end{tabular}

Table 2. The sensitivity matrix

\begin{tabular}{|c|c|c|c|c|c|c|c|c|c|c|c|c|c|c|c|}
\hline & C1 & |C2 & C3 & $\mathrm{C} 4$ & |c5 & |c6 & C7 & |c8 & C9 & C10 & C11 & C12 & C13 & |C14 & C15 \\
\hline $\mathrm{C} 1$ & 0 & \begin{tabular}{|l|}
0.04 \\
\end{tabular} & 0 & 0.13 & \begin{tabular}{|l|}
0.01 \\
\end{tabular} & 0 & 0 & 0 & 0 & 0 & 0 & 0 & \begin{tabular}{|l|l}
-0.10 \\
\end{tabular} & 0 & 0 \\
\hline $\mathrm{C} 2$ & -0.06 & 0 & 0 & 0 & 0 & 0 & 0.08 & 0.10 & 0.08 & -0.01 & 0.03 & 0 & 0.12 & \begin{tabular}{|l|} 
\\
\end{tabular} & -0.40 \\
\hline $\mathrm{C} 3$ & 0 & -0.10 & 0 & 0.04 & 0 & 0 & -0.15 & -0.11 & \begin{tabular}{|l|l}
-0.08 \\
\end{tabular} & \begin{tabular}{|l|}
-0.08 \\
\end{tabular} & 0 & 0 & \begin{tabular}{|l|l|}
-0.12 \\
\end{tabular} & \begin{tabular}{|l|}
0.10 \\
\end{tabular} & 0.45 \\
\hline $\mathrm{C4}$ & 0 & 0.13 & 0 & 0 & 0 & 0 & 0 & -0.40 & 0.10 & 0.05 & 0 & 0 & 0.08 & 0 & 0 \\
\hline $\mathrm{C5}$ & 0 & 0.09 & 0 & 0.05 & 0 & 0.10 & 0.03 & 0 & 0.03 & 0 & 0 & 0 & 0.02 & 0 & \begin{tabular}{|l|} 
\\
\end{tabular} \\
\hline C6 & 0 & 0 & 0 & 0 & 0 & 0 & 0.05 & 0.03 & 0.03 & 0 & 0 & 0 & 0.01 & 0 & -0.05 \\
\hline$\overline{C 7}$ & 0 & 0 & 0 & 0.01 & 0.01 & 0.13 & 0 & 0 & 0.03 & 0 & 0 & 0 & 0 & 0 & \begin{tabular}{|l|l|} 
& -0.3 \\
\end{tabular} \\
\hline $\mathrm{C} 8$ & 0 & 0 & 0 & 0.07 & 0.02 & 0.07 & 0.13 & 0 & 0.05 & 0 & 0.08 & 0.08 & 0.03 & \begin{tabular}{|l|}
-0.09 \\
\end{tabular} & \begin{tabular}{|l|l} 
& -0.07 \\
\end{tabular} \\
\hline C9 & 0 & 0.09 & 0 & 0.13 & 0.03 & 0.07 & 0 & 0 & 0 & 0 & 0.07 & 0 & 0.05 & 0 & 0 \\
\hline $\mathrm{C} 10$ & 0.24 & -0.07 & 0 & 0.15 & \begin{tabular}{|l|}
-0.04 \\
\end{tabular} & -0.40 & -0.30 & \begin{tabular}{|l|l|} 
\\
\end{tabular} & -0.20 & 0 & 0.13 & \begin{tabular}{|l|}
-0.16 \\
\end{tabular} & -0.24 & 0.53 & 0 \\
\hline C11 & 0 & 0 & 0 & 0.08 & 0 & 0 & 0 & 0 & 0 & 0.04 & 0 & 0 & 0.06 & 0 & 0 \\
\hline $\mathrm{C} 12$ & 0.04 & 0.03 & 0 & 0 & 0 & 0 & 0.05 & 0.04 & 0.01 & 0 & 0 & 0 & -0.02 & 0 & 0 \\
\hline $\mathrm{C} 13$ & -0.07 & 0 & 0 & 0.11 & 0.05 & 0.08 & 0.04 & 0.13 & 0.04 & \begin{tabular}{|l|l|}
-0.02 \\
\end{tabular} & 0.11 & 0.10 & 0 & -0.28 & 0 \\
\hline C14 & 0 & 0.01 & 0 & -0.01 & -0.01 & \begin{tabular}{|l}
-0.02 \\
\end{tabular} & \begin{tabular}{|l|}
-0.02 \\
\end{tabular} & -0.01 & \begin{tabular}{|c|}
-0.01 \\
\end{tabular} & 0 & -0.01 & 0.02 & 0.01 & 0 & 0 \\
\hline $\mathrm{C} 15$ & & 0.01 & 0 & 0.04 & 0.00 & 0.05 & 0.05 & 0.03 & $\mid-0.01$ & 0 & 0 & 0 & 0.01 & -0.02 & 0 \\
\hline
\end{tabular}

